\title{
Strain differences in latent inhibition
}

\author{
I. WEINER, I. HAIRSTON, M. SHAYIT, G. FELDMAN, and D. JOEL \\ Tel-Aviv University, Tel-Aviv, Israel \\ and \\ J. FELDON \\ Tel-Aviv University, Tel-Aviv, Israel \\ and Swiss Federal Institute of Technology, Institute of Toxicology, Schwerzenbach, Switzerland
}

\begin{abstract}
Latent inhibition (LI) - that is, retarded conditioning to a stimulus following its nonreinforced preexposure - was tested in inbred Buffalo Dark-Agouti (DA) rats. Unlike albino outbred Wistar rats, which showed $\mathrm{L}$ to both tone and flashing light in a conditioned emotional response (CER) procedure, DA rats showed LI to light but not to tone. The same pattern was obtained in DA rats in a two-way active-avoidance procedure. In addition, DA rats failed to show LI to white noise. LI to tone in CER was not restored by increasing the number of preexposures or by the administration of haloperidol. This is a first demonstration of strain differences in LI acquisition. Since LI disruption characterizes specific neuropsychiatric disorders, the elucidation of the mechanisms underlying the failure to develop LI, when this failure is not caused by external manipulations (e.g., by a drug or a lesion), may be important for understanding the neural substrates of this deficit.
\end{abstract}

If an organism is repeatedly preexposed to a stimulus (e.g., tone or light) in the absence of reinforcement, it subsequently develops a weaker association between this stimulus and a reinforcer (e.g., a footshock) than does a nonpreexposed organism. This retarded conditioning to the preexposed as compared to the nonpreexposed stimulus is latent inhibition (LI). LI is considered to index the capacity of organisms to ignore stimuli that predict no significant consequences; it can be demonstrated in a variety of classical and instrumental conditioning procedures and in many mammalian species, including humans (Lubow, 1989; Lubow \& Gewirtz, 1995; Lubow, Weiner, \& Schnur, 1981). A recent review of human LI data has indicated that LI is similar in humans and animals, and that it can be viewed as reflecting the operation of analogous processes across species (Lubow \& $\mathrm{Ge}$ wirtz, 1995).

LI has received considerable attention in the animal learning literature over the past 25 years (see, e.g., Bouton, 1993; Hall, 1991; Lubow, 1989; Lubow et al., 1981; Mackintosh, 1975; Moore \& Stickney, 1980; Pearce \& Hall, 1980; Schmajuk, Lam, \& Gray, 1996; Schmajuk \& Moore, 1985). Earlier, the extensive efforts to understand LI were directed at behavioral analyses of the phenomenon. More recently, a considerable body of data has been accumulated on the neural substrates of LI, spawned by the proposition that the disruption of LI may provide an

This research was supported by grants from the Israel Science Foundation, founded by the Israel Academy of Sciences and Humanities, and the Josef Buchmann Doctoral Fellowship Fund to D.J. Correspondence concerning this article should be addressed to I. Weiner, Department of Psychology, Tel-Aviv University, Ramat-Aviv, Tel-Aviv 69978 Israel (e-mail: weiner@freud.tau.ac.il). animal model for the widely described failure of schizophrenic patients to ignore irrelevant stimuli (J. A. Gray, Feldon, Rawlins, Hemsley, \& Smith, 1991; Robbins, 1990; Weiner, 1990). This has given rise to neural (J. A. Gray et al., 1991; Weiner, 1990; Weiner \& Feldon, 1997) and neural-network (Gluck \& Myers, 1993; Schmajuk et al., 1996) models of LI, as well as to extensive research efforts aimed at elucidating the behavioral, pharmacological, and neural mechanisms of this phenomenon.

As part of our own research on the LI model of schizophrenia, we began testing LI in Buffalo Dark-Agouti (DA) rats, a pigmented inbred strain, using an off-baseline conditioned emotional response (CER) procedure, with tone as the preexposed stimulus. Unlike the outbred Wistar rat strain commonly used in our laboratory, the DA rats failed to show LI to tone, suggesting that there may be important strain differences in LI development. We conducted the present series of experiments to investigate this possibility. Since DA rats are heavily reliant on and particularly proficient in using visual cues (Aggleton, 1996; Birch \& Jacobs, 1979; Gaffan \& Eacott, 1995), we compared the effects of preexposure to tone and light in DA and Wistar rats in the CER procedure (Experiments 1-3). Because DA rats failed to show LI to tone, Experiments 4 and 5 tested whether LI to tone could be restored by two manipulations that are known to potentiate the LI effect-increasing the number of nonreinforced preexposures (Lubow, 1989; Lubow et al., 1981) and treatment with the dopamine antagonist haloperidol (see, e.g., Killcross, Dickinson, \& Robbins, 1994; Weiner \& Feldon, 1987). To test whether DA rats' failure to show LI to tone is task-specific, Experiment 6 tested LI to tone and light in a two-way active-avoidance procedure. Finally, to test whether the inability to show LI is 
modality-specific, Experiments 7 and 8 tested LI to white noise in the CER procedure.

\section{METHOD}

\section{Subjects}

Male Wistar rats (Tel-Aviv University Medical School, Israel) and DA rats (obtained from Harlan, England, and bred in Tel-Aviv University Medical School) approximately 4 months old, weighing $250-300 \mathrm{~g}$, were housed in groups of four under reversed-cycle lighting (lights on: 1900-0700).

\section{Apparatus and Procedure}

Latent inhibition in the conditioned emotional response (CER) procedure. The apparatus consisted of four Campden Instruments rodent test chambers (Model 410), each set in a ventilated sound-attenuating Campden Instruments chest (Model 412). A drinking bottle could be inserted into the chamber through a 0.5 $\mathrm{cm}$-diameter hole located at the center of the left wall $2.5 \mathrm{~cm}$ above the grid floor. When the bottle was not present, the hole was covered by a plastic lid. Licks were detected by a Campden Instruments drinkometer circuit (Model 453). The preexposed to-be-conditioned stimuli were a $5-\mathrm{sec}, 2.8-\mathrm{kHz}, 80-\mathrm{dB}$ tone produced by a Sonalert module (Model SC 628), a 5-sec 85-dB white noise produced by a Campden Instruments white-noise generator (Model 530), or a light flashing at a rate of $1.3 \mathrm{~Hz}$ for $5 \mathrm{sec}$, generated from the houselight located at the center of the ceiling. Shock was supplied through the floor by a Campden Instruments shock generator (Model 521/C) and a shock scrambler (Model $521 / \mathrm{S}$ ) set at $0.5 \mathrm{~mA}$ for a 1 -sec duration. Equipment programming and data recording were computer controlled.

Prior to the beginning of each LI experiment, rats were handled for about 2 min daily for 6 days. A 23-h water-restriction schedule was initiated simultaneously with handling and was continued throughout the behavioral testing. Water in the test apparatus was given in addition to the daily ration of $1 \mathrm{~h}$ given in the home cages.

The LI procedure consisted of the following stages:

Baseline. On each of 6 days, rats were individually placed into the experimental chamber and allowed to drink for $15 \mathrm{~min}$.

Preexposure. With the water bottle removed, each rat was placed in the experimental chamber. In Experiments 1-3, 5, 7, and 8, the preexposed (PE) rats received forty 5 -sec presentations of the to-beconditioned stimulus (tone in Experiments 1-3, 5, and 7, light in Experiments 1, 2, 5, and 8, white noise in Experiments 7 and 8) with a fixed interval of $50 \mathrm{sec}$. The nonpreexposed (NPE) rats were confined to the chamber for an identical period without receiving the stimulus. In Experiment 4, the PE rats received either 40 or 80 5 -sec presentations of the tone. Half of the rats in the NPE group were confined to the chamber for a time identical to that of the 40 PE group and the other half for a time identical to that of the $80 \mathrm{PE}$ group, without receiving the tone.

Conditioning. With the water bottle removed, each rat was given two stimulus (tone, light, or white noise)-shock pairings 5 and 10 min after the start of the session. The parameters of the stimuli were identical to those used in the preexposure stage. The $0.5-\mathrm{mA}$, $1-\mathrm{sec}$ shock immediately followed stimulus termination. After the second pairing, the rats were left in the experimental chamber for an additional $5 \mathrm{~min}$.

Rebaseline. Each rat was given a drinking session as in baseline training.

Test. Each rat was placed in the chamber and allowed to drink from the bottle. When the rat completed 75 licks, the stimulus (tone, light, or white noise) was presented and lasted for $300 \mathrm{sec}$. The following times were recorded: time to first lick, time to complete licks $1-50$, time to complete licks $51-75$ (period A, pretone), and time to complete licks 76-100 (period B, tone-on). The amount of suppression of licking was measured using a suppression ratio,
$A /(A+B)$. This ratio is inversely related to the amount of lick suppression: A high suppression ratio expresses a low suppression of drinking, whereas a low suppression ratio indexes a high suppression of drinking. Preexposure effect is therefore manifested by a decrease in the suppression of drinking and an increase in the suppression ratio.

The stages of preexposure, conditioning, rebaseline, and test were given $24 \mathrm{~h}$ apart.

Latent inhibition in two-way active avoidance. The apparatus consisted of four identical Campden Instruments shuttle boxes, measuring $48.5 \times 23 \times 20 \mathrm{~cm}$. The barrier between the two compartments of the box consisted of an aluminum wall with a central inverted-U-shaped gate $(12 \mathrm{~cm}$ high, $10 \mathrm{~cm}$ wide). Each box was set in a ventilated, sound-attenuating chest. The conditioned stimulus was either a $10-\mathrm{sec}$ light, generated from two light sources each located at the center of one of the two walls facing the barrier, flashing at a rate of $1.3 \mathrm{~Hz}$, or a $10-\mathrm{sec}, 2.8-\mathrm{kHz}, 80-\mathrm{dB}$ tone produced by a Sonalert module (Model SC 628). Shock was supplied through the grid floor by a Campden Instruments scrambled shock generator (Model 521C) set at $0.5-\mathrm{mA}$ intensity. Equipment programming and data recording were computer controlled.

The LI procedure included the following stages given $24 \mathrm{~h}$ apart:

Habituation to the apparatus. Each rat was placed in the shuttle box for $30 \mathrm{~min}$.

Preexposure. Each rat was placed in the shuttle box for $60 \mathrm{~min}$. The PE rats received 50 stimulus (tone or light) presentations, with a variable interstimulus interval of $50 \mathrm{sec}$. The NPE rats were confined to the shuttle box for an identical period of time without receiving the stimulus.

Two-way avoidance. Each rat was placed in the shuttle box with the houselight on and received 100 avoidance trials, presented on a variable-interval 60 -sec schedule ranging from 10 to $110 \mathrm{sec}$. Each avoidance trial began with a $10-\mathrm{sec}$ presentation of the stimulus (tone or flashing light) followed by a 5 -sec shock, the stimulus remaining on during the shock. If the rat crossed the barrier to the opposite compartment during the 10 -sec stimulus, the stimulus was terminated and no shock was delivered (avoidance response). A crossing response during shock terminated the stimulus and the shock. If the rat failed to cross during the entire stimulus-shock trial, the stimulus and the shock terminated after $15 \mathrm{sec}$. The number of avoidance responses was recorded in 10-trial blocks.

\section{Drugs}

In Experiment 5, 0.1 -mg/kg haloperidol (prepared from an ampoule containing $5 \mathrm{mg}$ of haloperidol in a $1-\mathrm{ml}$ solvent containing $6 \mathrm{mg}$ of lactic acid [Abic LTD, Israel] diluted in an appropriate volume of saline) or an equivalent volume of vehicle was injected i.p. $45 \mathrm{~min}$ prior to preexposure and $45 \mathrm{~min}$ prior to conditioning. The rebaseline and test stages were conducted without drugs.

\section{Experimental Design}

Experiment 1: LI to tone or light in DA rats in the CER procedure. Forty-eight DA rats were allocated randomly to four experimental groups in a $2 \times 2$ factorial design with main factors of preexposure $(0,40)$ and stimulus (tone, light). Data on five rats were lost because of apparatus failure. The final analysis included 43 animals, with the following number of animals in each condition: NPE tone, 12; NPE light, 11; PE tone, 8; PE light, 12.

Experiment 2: LI to tone or light in Wistar rats in the CER procedure. Fifty-six Wistar rats were allocated randomly to four experimental groups in a $2 \times 2$ factorial design with main factors of preexposure $(0,40)$ and stimulus (tone, light). Data on 2 rats were lost because of apparatus failure. The final analysis included 54 animals, with the following number of animals in each condition: NPE tone, 14; NPE light, 13; PE tone, 14; PE light, 13.

Experiment 3: LI to tone in DA and Wistar rats in the CER procedure. Sixteen Wistar rats and $16 \mathrm{DA}$ rats were allocated to four experimental groups in a $2 \times 2$ factorial design with main fac- 
tors of preexposure $(0,40)$ and strain (Wistar, DA). Data on 1 rat were lost because of apparatus failure. The final analysis included 31 animals, with the following number of animals in each condition: NPE DA, 7; NPE Wistar, 8; PE DA, 8; PE Wistar, 8.

Experiment 4: $L I$ to tone in DA rats with 40 or 80 preexposures. Twenty-four DA rats were allocated randomly to three PE conditions $(0,40,80)$. The NPE group was divided into two subgroups in order to control for the different duration of time spent in the apparatus by the 40 and $80 \mathrm{PE}$ conditions. Data on 2 rats were lost because of apparatus failure. The final analysis included 22 animals, with the following number of animals in each condition: NPE (40), 3; NPE (80), 4; PE (40), 8; PE (80), 7.

Experiment 5: The effects of haloperidol on $\mathrm{LI}$ to tone or light in DA rats. Fifty-six DA rats were randomly allocated to eight experimental groups in a $2 \times 2 \times 2$ factorial design with main factors of preexposure $(0,40)$, stimulus (tone, light), and drug (vehicle [VEH], haloperidol [HAL]). Data on 2 rats were lost because of apparatus failure. The final analysis included 54 animals, with the following number of animals in each condition: NPE tone VEH, 6; NPE tone HAL, 6; NPE light VEH, 6; NPE light HAL, 5; PE tone VEH, 8; PE tone HAL, 7; PE light VEH, 8; PE light HAL, 8.

Experiment 6: $\mathrm{LI}$ to tone or light in DA rats in two-way activeavoidance procedure. Thirty-two DA rats were randomly allocated to four experimental groups ( $n$ per group $=8$ ) in a $2 \times 2$ factorial design with main factors of preexposure $(0,50)$ and stimulus (tone, light).

Experiment 7: LI to tone or white noise in DA rats in the CER procedure. Forty-four DA rats were randomly allocated to four experimental groups in a $2 \times 2$ factorial design with main factors of preexposure $(0,40)$ and stimulus (tone, white noise). Data on 2 rats were lost because of apparatus failure. The final analysis included 42 animals, with the following number of animals in each condition: NPE tone, 10; NPE white noise, 10; PE tone, 11; PE white noise, 11.

Experiment 8: LI to light or white noise in DA rats in the CER procedure. Forty-four DA rats were allocated randomly to four experimental groups in a $2 \times 2$ factorial design with main factors of preexposure $(0,40)$ and stimulus (light, white noise). Data on 2 rats were lost because of apparatus failure. The final analysis included 42 animals, with the following number of animals in each condition: NPE light, 11; NPE white noise, 11; PE light, 10; PE white noise, 10.

\section{RESULTS}

\section{Experiment 1: LI to Tone or Light in DA Rats in the CER Procedure}

$2 \times 2$ analyses of variance (ANOVAs) conducted on the times to complete licks $1-50$ and $51-75$ in the absence of the stimulus yielded no significant results. The mean suppression ratios of the PE and NPE groups conditioned with tone or with light are presented in Figure 1. As can be seen, when light was used, the PE rats showed less suppression of drinking than did the NPE rats - that is, there was LI. In contrast, when tone was used, there was no LI-that is, the PE and NPE groups showed a similar level of suppression. Moreover, the overall level of suppression in both the PE and NPE groups conditioned with tone was similar to the level of suppression seen in the NPE group conditioned with light - that is, the absence of LI in the tone condition was due to high suppression in the PE group. These outcomes were supported by a $2 \times 2$ ANOVA with main factors of preexposure and stimulus that yielded a significant preexposure $\times$ stimulus interaction $[F(1,39)=4.62, p<.05]$. Post hoc two-

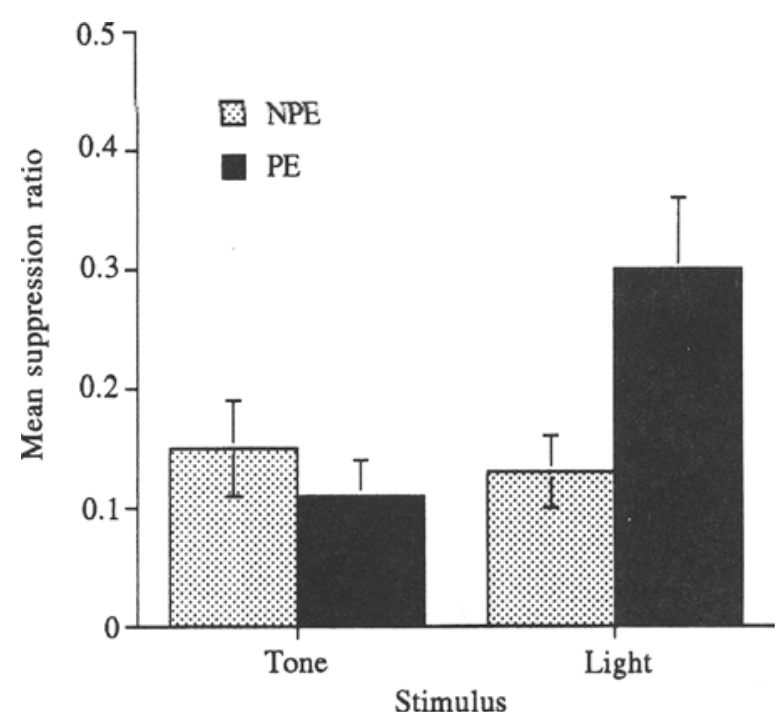

Figure 1. Means and standard errors of suppression ratios of the preexposed (PE) and nonpreexposed (NPE) DA rats conditioned with tone or light.

tailed $t$ tests based on the error term derived from the ANOVA comparing the PE and NPE groups within each stimulus condition yielded a significant difference - that is, an LI effect in the light $[t(39)=24.3, p<.001]$ but not in the tone $[t(39)=.05$, n.s. $]$ condition.

\section{Experiment 2: LI to Tone or Light in Wistar Rats in the CER Procedure}

$2 \times 2$ ANOVAs conducted on the times to complete licks $1-50$ and $51-75$ in the absence of the stimulus yielded no significant results. The mean suppression ra-

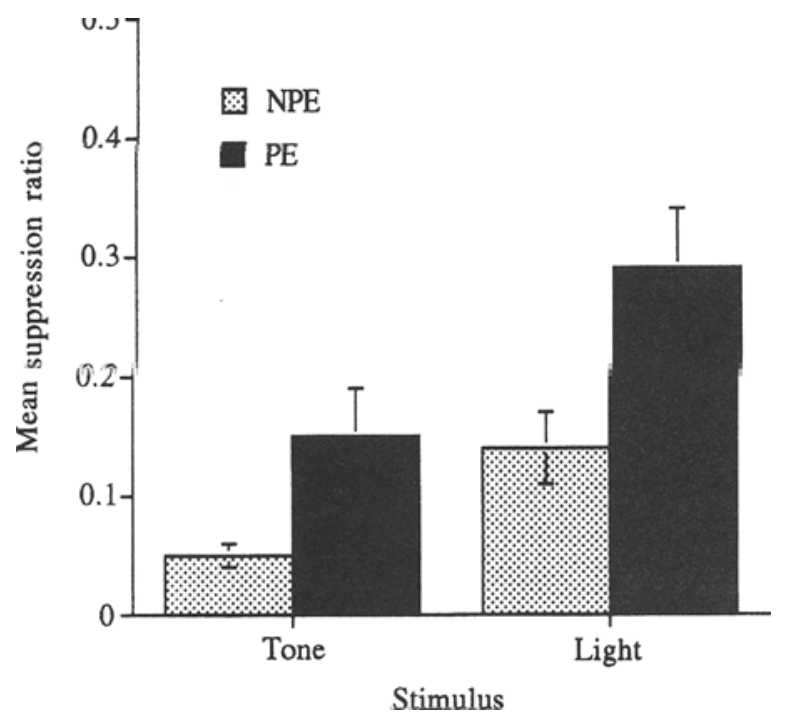

Figure 2. Means and standard errors of suppression ratios of the preexposed (PE) and nonpreexposed (NPE) Wistar rats conditioned with tone or light. 
tios of the PE and NPE groups conditioned with tone or with light are presented in Figure 2. As can be seen, with both stimuli, there was a clear LI effect-that is, the PE rats showed less suppression of drinking than did the NPE rats. In addition, there was a stronger overall suppression of drinking in the presence of the tone than in the presence of light. These outcomes were supported by a $2 \times 2$ ANOVA with main factors of preexposure and stimulus that yielded significant main effects of preexposure $[F(1,50)=13.44, p<.001]$ and of stimulus $[F(1,50)=13.19, p<.001]$.

\section{Experiment 3: LI to Tone in DA and Wistar Rats in the CER Procedure}

$2 \times 2$ ANOVAs conducted on the times to complete licks $1-50$ and $51-75$ in the absence of the stimulus yielded no significant results. The mean suppression ratios of the PE and NPE DA and Wistar rats are presented in Figure 3. As can be seen, there was a clear LI effect in Wistar rats-that is, the PE animals exhibited lower suppression of drinking than did the NPE animals. In contrast, PE DA rats showed levels of suppression of drinking similar to their NPE counterparts-that is, there was no LI. These outcomes were supported by a $2 \times 2$ ANOVA with main factors of preexposure and strain that yielded significant main effects of preexposure $[F(1,27)=4.2$, $p<.05]$ and strain $[F(1,27)=6.94, p<.05]$, as well as a significant preexposure $\times$ strain interaction $[F(1,27)$ $=4.62, p<.05]$. Posthoc two-tailed $t$ tests based on the error term derived from the ANOVA comparing the PE and NPE groups within each strain yielded a significant difference-that is, an LI effect in the Wistar $[t(27)=$ $2.97, p<.01]$ but not in the DA $[t=.07$, n.s. $]$ rats.

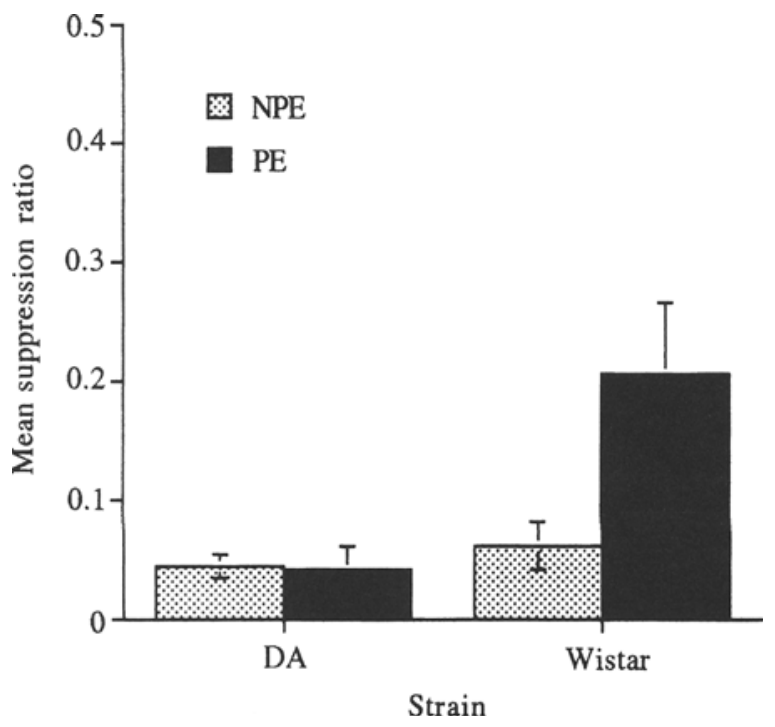

Figure 3. Means and standard errors of suppression ratios of the preexposed (PE) and nonpreexposed (NPE) DA and Wistar rats conditioned with tone.

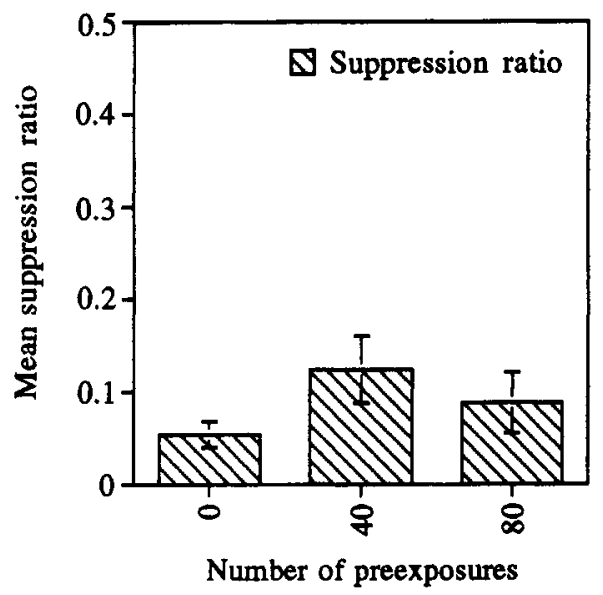

Figure 4. Means and standard errors of suppression ratios of DA rats conditioned with tone in three preexposure conditions0,40 , or 80 preexposures.

\section{Experiment 4: LI in DA Rats \\ With 40- or 80-Tone Preexposures}

Since there were no significant differences between the two NPE groups on any of the measures, the data on the two groups were combined for statistical analysis. One-way ANOVAs conducted on the times to complete licks $1-50$ and $51-75$ in the absence of the stimulus yielded no significant results. The mean suppression ratios in the three preexposure conditions- 0,40 , or $80-$ are presented in Figure 4 . As can be seen, rats receiving 40- or 80-tone preexposures exhibited a level of suppression similar to that of the NPE group - that is, there was no LI at both preexposure levels. A one-way ANOVA with main factor of preexposure $(0,40,80)$ yielded no significant outcomes.

\section{Experiment 5: The Effects of Haloperidol on $\mathrm{Ll}$ to Tone or Light in DA Rats}

$2 \times 2$ ANOVAs conducted on the times to complete licks $1-50$ and $51-75$ in the absence of the stimulus yielded no significant results. The mean suppression ratios of the vehicle- or haloperidol-treated PE and NPE groups conditioned with tone or light are presented in Figure 5. As can be seen, DA rats trained with light showed $\mathrm{LI}$ - that is, lower suppression in the PE as compared with the NPE group - whereas those trained with tone failed to show Ll. Haloperidol treatment tended to reduce suppression in both the PE and NPE groups, but was without effect on LI in both stimulus conditions. These outcomes were supported by a $2 \times 2 \times 2$ ANOVA with main factors of preexposure, stimulus, and drug that yielded significant main effects of preexposure $[F(1,46)$ $=14.35, p<.001]$ and stimulus $[F(1,46)=9.92, p<.01]$, as well as a significant preexposure $\times$ stimulus interaction $[F(1,46)=17.56, p<.0001]$. Post hoc two-tailed $t$ tests based on the error term derived from the ANOVA, com- 


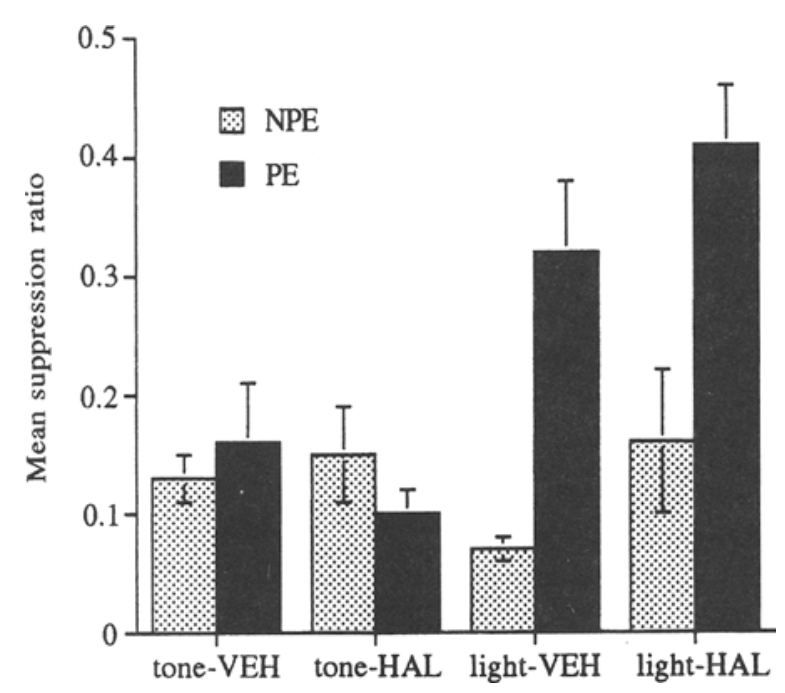

Figure 5. Means and standard errors of suppression ratios of the preexposed (PE) and nonpreexposed (NPE) DA rats in the four conditions-tone-vehicle (tone-VEH), tone-haloperidol (tone-HAL), light-vehicle (light-VEH), and light-haloperidol (light-HAL).

paring the PE and NPE groups in each of the stimulusdrug conditions, yielded a significant difference- that is, an LI effect in the light-vehicle $[t(46)=4.15, p<.001]$ and light-haloperidol $[t(46)=4.12, p<.001]$ conditions but not in the tone-vehicle $[t(46)=0.46$, n.s. $]$ and the tone-haloperidol $[t(46)=0.87, \mathrm{n} . \mathrm{s}$. $]$ conditions.

\section{Experiment 6: LI to Tone or Light in DA Rats in Two-Way Active Avoidance-Procedure}

Figure 6 presents the mean number of avoidance responses, in 10-trial blocks, in the PE and NPE groups

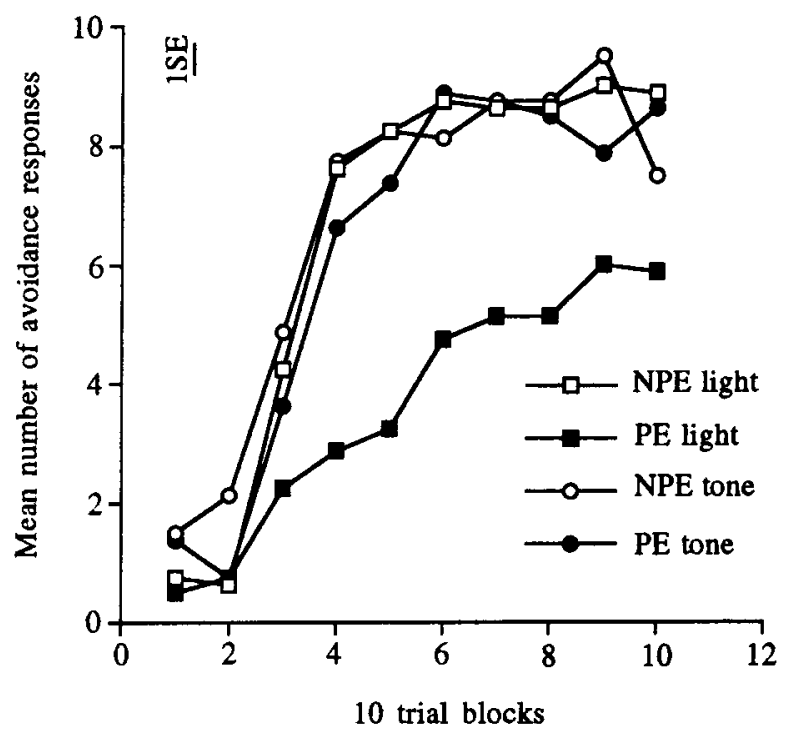

Figure 6. Mean number of avoidance responses in 10-trial blocks in the preexposed (PE) and nonpreexposed (NPE) DA rats conditioned with tone or light. conditioned with tone or light. As can be seen, in the case of tone CS, the PE and NPE groups improved similarly with training and reached similar levels of avoidance by the end of training, which indicates no preexposure effect. In contrast, in the case of light $\mathrm{CS}$, although both groups improved with training, the PE group exhibited poorer avoidance than did the NPE group - that is, there was LI. Moreover, the acquisition curves of both the PE and NPE groups that were conditioned with tone were similar to the acquisition curve of the NPE group that was conditioned with light - that is, the absence of LI in the tone condition was due to the fast rate of acquisition in the PE group. These outcomes were supported by a $2 \times 2$ ANOVA with main factors of preexposure and stimulus and a repeated measurements factor of 10-trial blocks that yielded a significant effect of blocks $[F(9,252)=80.82, p<.0001]$ and of the linear and quadratic trends of this factor $[F(1,28)=219.25, p<.0001$, and $F(1,28)=166.10$, $p<.0001$, respectively], a significant main effect of preexposure $[F(1,28)=6.42, p<.05]$, significant quadratic trends of the stimulus $\times$ blocks and of the preexposure $\times$ blocks interactions $[F(1,28)=6.68, p<.05$, and $F(1,28)=11.57, p<.01$, respectively], as well as a significant preexposure $\times$ stimulus $\times$ blocks interaction $[F(9,252)=2.38, p<.05]$ and a significant quadratic trend of this interaction $[F(1,28)=6.58, p<.05]$.

\section{Experiment 7: LI to Tone or White Noise in DA Rats in the CER Procedure}

$2 \times 2$ ANOVAs conducted on the times to complete licks $1-50$ and $51-75$ in the absence of the stimulus yielded no significant outcomes. The mean suppression ratios of the PE and NPE groups conditioned with tone or white noise are presented in Figure 7. As can be seen, there was no difference in suppression between the PE and the NPE groups conditioned with tone or white noise-that is, neither stimulus produced LI. The white noise tended to generate more suppression than did the tone. A $2 \times 2$ ANOVA with main factors of preexposure and stimulus yielded only a nearly significant main effect of stimulus $[F(1,38)=3.81, p=.058]$.

\section{Experiment 8: LI to Light or White Noise in DA Rats in the CER Procedure}

$2 \times 2$ ANOVAs conducted on the times to complete licks $1-50$ and $51-75$ in the absence of the stimulus yielded no significant outcomes. The mean suppression ratios of the PE and NPE groups conditioned with light or white noise are presented in Figure 8. As can be seen, when light was used, the PE rats showed less suppression of drinking than did the NPE rats - that is, there was LI. In contrast, when white noise was used, there was no LI-that is, the PE and NPE groups showed a similar level of suppression. Moreover, the overall level of suppression in both the PE and NPE groups that were conditioned with white noise was similar to the level of suppression seen in the NPE group that was conditioned with light - that is, the absence of LI in the white-noise 
condition was due to high suppression in the PE group. These outcomes were supported by a $2 \times 2$ ANOVA with main factors of preexposure and stimulus that yielded a significant preexposure $\times$ stimulus interaction $[F(1,38)=$ $9.03, p<.01]$. Post hoc two-tailed $t$ tests based on the error term derived from the ANOVA comparing the PE and the NPE groups within each stimulus condition yielded a significant difference - that is, an LI effect in the light $[t(38)=3.31, p<.01]$ but not in the whitenoise $[t(38)=0.94$, n.s. $]$ condition.

\section{DISCUSSION}

In the CER procedure, outbred Wistar rats developed LI to a tone as well as to a flashing-light stimulus, whereas the inbred DA strain developed LI to the flashing light but failed to show LI to tone. LI to light but not to tone was also obtained in the DA strain in the two-way active-avoidance procedure. In addition, DA rats failed to show LI in the CER procedure when white noise was used as the PE stimulus.

The absence of LI to tone in DA rats was obviously not due to a general inability of this strain to develop LI, inasmuch as they showed normal LI to the flashing light. In addition, the fact that the same differentiation in LI to tone and light was obtained in the two-way active-avoidance procedure demonstrates that the failure to develop LI to tone was not task specific. Finally, the inability to develop LI was not restricted to tone, but appears rather to be modality specific, inasmuch as DA rats also failed to show LI to another auditory stimulus - white noise.

These results suggest that there is a difference in the processing of auditory as opposed to visual stimuli in DA rats. However, DA rats acquired the CER to tone as readily as did Wistar rats. Similarly, the acquisition of

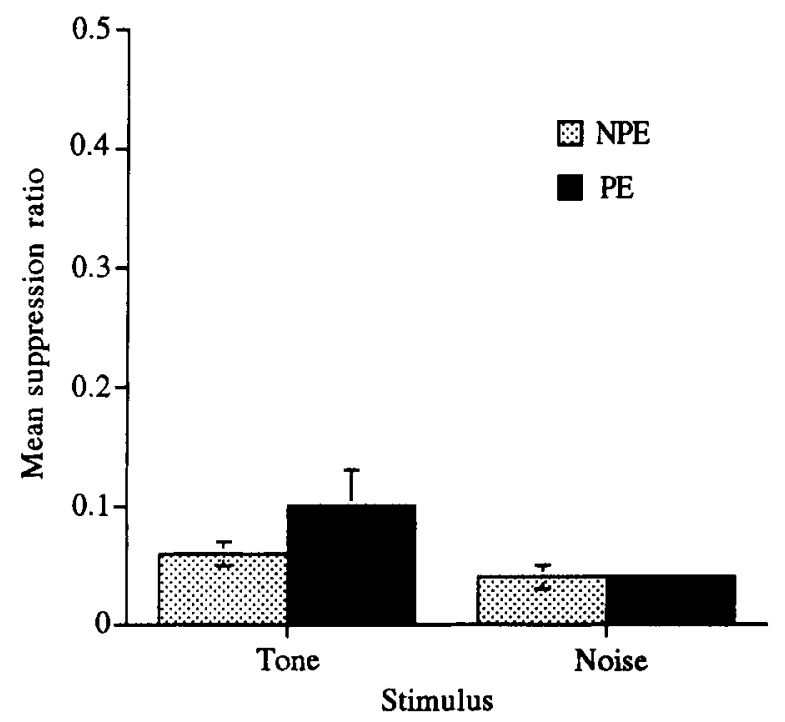

Figure 7. Means and standard errors of suppression ratios of the preexposed (PE) and nonpreexposed (NPE) DA rats conditioned with tone or white noise (Noise).

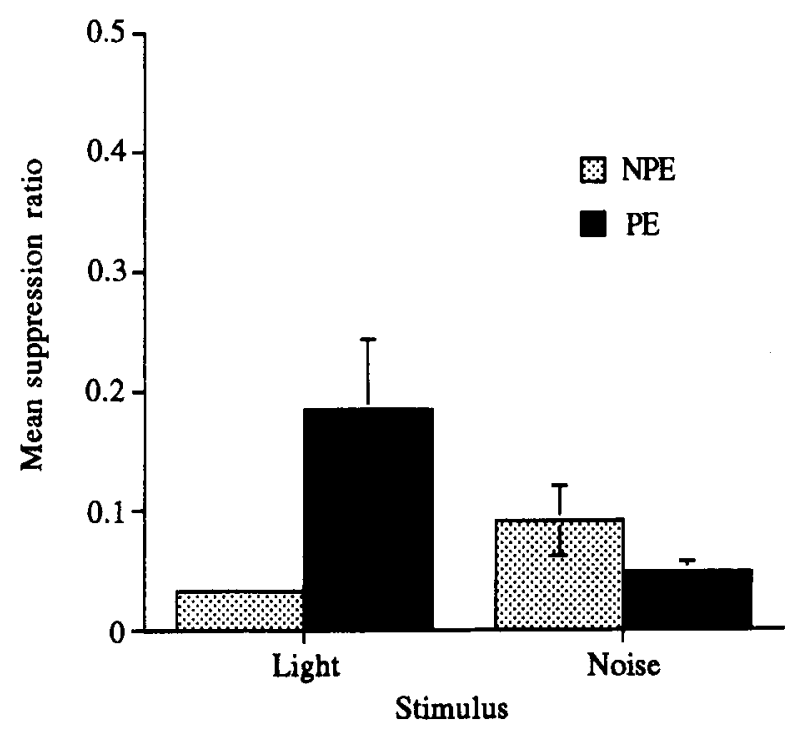

Figure 8. Means and standard errors of suppression ratios of the preexposed (PE) and nonpreexposed (NPE) DA rats conditioned with either light or white noise (Noise).

two-way active avoidance with tone as the warning stimulus was unimpaired in these rats. This indicates that regular conditioning with auditory stimuli, both classical and operant, is unimpaired in DA rats. Clearly, such intact conditioning also rules out a primary auditory deficit. Consequently, it can be concluded that the difference in processing of auditory as opposed to visual stimuli in DA rats is specific to $L I$.

Intact learning versus impaired LI with auditory stimuli implies that the mechanisms governing regular conditioning (i.e., operating in the NPE animals) are different from those governing the development of LI (i.e., operating in the PE animals) and that the latter are disrupted/inoperative in DA rats conditioned with auditory stimuli. Different mechanisms underlying LI versus regular conditioning have also been suggested by drug and lesion studies. For example, amphetamine and hippocampal lesion abolish LI but do not affect, or even facilitate, regular conditioning (Weiner, 1990). Interestingly, Sotty, Sandner, and Gosselin (in press) have recently shown that nonreinforced stimulus preexposure followed by conditioning produces a distinct pattern of c-fos immunolabeling in rats' brain in comparison with that produced by conditioning alone.

As to the reasons underlying the failure of auditory stimuli to yield LI in DA rats, one can only speculate. The mechanisms underlying the development of LI remain a matter of debate; however, most current accounts of LI (see, e.g., Bouton, 1993; Gluck \& Myers, 1993; Hall, 1991; Lubow, 1989; Lubow \& Gewirtz, 1995; Lubow et al., 1981; Mackintosh, 1975; Pearce \& Hall, 1980; Schmajuk et al., 1996; Schmajuk \& Moore, 1985; Wagner, 1976, 1978) agree that some kind of predictive relationship between the PE stimulus and some other antecedent or consequent event(s) is (are) acquired dur- 
ing preexposure and that this affects subsequent formation and/or expression of the stimulus-reinforcement association in conditioning. Absence of LI can therefore stem from processing failure at either preexposure or conditioning.

We tried two manipulations which are known to increase and/or reinstate LI after its disruption-increasing the number of preexposures (Lubow, 1989; Lubow et al., 1981) and the administration of the dopaminergic blocker haloperidol (Killcross et al., 1994; Weiner \& Feldon, 1987). Both failed to produce LI to tone in DA rats.

Because haloperidol did not enhance the LI effect in animals conditioned with light, it could be argued that this drug is ineffective in DA rats. However, it is well documented that the LI-potentiating effect of haloperidol is more readily observed under conditions in which no-drug animals do not show robust LI (Dunn, Atwater, \& Kilts, 1993; Feldon \& Weiner, 1991; Killcross et al., 1994; Peters \& Joseph, 1993; Weiner, Kidron, Tarrasch, Arnt, \& Feldon, 1994; Weiner, Shadach, Barkai, \& Feldon, 1997; Weiner, Shadach, Tarrasch, Kidron, \& Feldon, 1996); therefore, the lack of a haloperidol-induced enhancement of LI in the light condition is consistent with previous reports. Furthermore, to date, haloperidol has been shown to reinstate LI following all drug and lesion manipulations which disrupted LI (for a review, see Weiner \& Feldon, 1997). Therefore, the failure of haloperidol to reinstate LI in the tone condition appears to provide the first demonstration of "haloperidol-resistant" LI disruption.

There is abundant evidence that DA blockers do not affect the acquisition of LI - that is, learning about the nonreinforced stimulus in preexposure-but rather affect the expression of this learning in conditioning, when the PE stimulus is followed by reinforcement (Peters \& Joseph, 1993; Weiner \& Feldon, 1997; Weiner et al., 1997; Weiner et al., 1996). Consequently, the failure of haloperidol to reinstate $\mathrm{LI}$ to tone in DA rats suggests that the absence of $\mathrm{LI}$ to this stimulus is not due to processes taking place in the conditioning stage, but rather may reflect a failure to process the nonreinforced stimulus in the preexposure stage. Consistent with the latter possibility is the finding that increasing the number of preexposures to tone was ineffective in reinstating LI. While there remains a possibility that a still higher number of preexposures would have restored LI, 80 preexposures may be considered as very extensive in light of the fact that LI is typically obtained in the CER procedure with a number of preexposures ranging from 20 to 40 (Lubow, 1989). Thus, the fact that neither haloperidol nor an increased number of preexposures reinstated LI to tone in DA rats may be taken as an indication that these rats failed to process the PE stimulus in the preexposure stage.

Our results do not make clear which critical parameters of the tone make it "LI resistant." One such parameter could be that of stimulus salience. Given the evidence that LI magnitude is a positive function of stimulus inten- sity (Lubow, 1989) and that visual stimuli are highly salient for DA rats (Aggleton, 1996; Birch \& Jacobs, 1979; Gaffan \& Eacott, 1995), it is possible that tone is less salient than light. Although we did not obtain evidence for lower salience of tone in regular conditioning, salience level may exert different effects during classical conditioning and nonreinforced stimulus preexposure. Thus, during the latter, the critical associations involve stimulusno consequence, stimulus-stimulus, and context-stimulus associations (Bouton, 1993; Gluck \& Myers, 1993; Hall, 1991; Lubow, 1989; Lubow \& Gewirtz, 1995; Lubow et al., 1981; Mackintosh, 1975; Pearce \& Hall, 1980; Schmajuk et al., 1996; Schmajuk \& Moore, 1985; Wagner, 1976, 1978), all of which may be more sensitive to low salience than stimulus-US associations.

It is of interest to note that we recently found that, in Wistar rats, the effects of DA agonists and antagonists on LI depend on the nature of the stimulus, so that with certain stimuli LI is undisruptable by amphetamine and unpotentiated by haloperidol (Ruob, Elsner, Weiner, \& Feldon, 1997). Since, in the case of haloperidol, PE animals received a low number of preexposures, which did not yield LI in control rats, and haloperidol failed to restore LI, these conditions are very similar to those obtained here in DA rats with tone. Thus, the nature of the stimulus seems to exert a pervasive influence on the mechanisms governing LI development or disruption.

Whatever the mechanisms underlying the failure of DA rats to show LI to auditory stimuli may be, the present results have two important implications. First, they provide a demonstration of strain differences in the acquisition of LI and thus highlight, for the first time, potentially confounding variables arising from the use of different strains for LI research. Second, since LI disruption characterizes specific neuropsychiatric disorders - such as some subpopulations of schizophrenic patients (Baruch, Hemsley, \& J. A. Gray, 1988a; Dunn \& Scibilia, 1996; N. S. Gray, Pickering, Hemsley, Dawling, \& J. A. Gray, 1992; N. S. Gray, Pilowsky, J. A. Gray, \& Kerwin, 1995; Vaitl \& Lipp, 1997; but see Swerdlow, Braff, Hartston, Perry, \& Geyer, 1996) and children with attention deficit disorder (Lubow \& Josman, 1993), as well as normal individuals scoring high on scales of schizotypy (Baruch, Hemsley, \& J. A. Gray, 1988b; De la Casa, Ruiz, \& Lubow, 1993; Lipp \& Vaitl, 1992; Lubow, Ingberg-Sachs, Zalstein-Orda, \& Gewirtz, 1992)- the elucidation of the mechanisms underlying failure to develop LI in certain strain of rats may be of paramount importance for understanding the neural substrates of this deficit. In this context, it is particularly important that a strain-dependent failure to show LI is not brought about by external manipulations (e.g., by a drug or a lesion) and, therefore, may provide a better analog of naturally occurring LI deficits. For example, in view of the results of Sotty et al. (in press), cited above, it would be of great interest to compare the patterns of c-fos immunolabeling in the brains of DA rats that follow preexposure and conditioning to tone or light. 


\section{REFERENCES}

AgGleton, J. P. (1996). The ability of different strains of rats to acquire a visual nonmatching-to-sample task. Psychobiology, 24, 44-48.

Baruch, I., Hemsley, D., \& Gray, J. A. (1988a). Differential performance of acute and chronic schizophrenics in a latent inhibition task. Journal of Nervous \& Mental Disease, 176, 598-606.

Baruch, I., Hemsley, D. R., \& Gray, J. A. (1988b). Latent inhibition and "psychotic proneness" in normal subjects. Personality \& Individual Differences, 9, 777-783.

BIRCH, D., \& JACOBS, G. H. (1979). Spatial contrast sensitivity in albino and pigmented rats. Vision Research, 19, 933-937.

Bouton, M. E. (1993). Context, time, and memory retrieval in the interference paradigms in Pavlovian learning. Psychological Bulletin, $114,80-99$.

De la CASA, L. G., Ruiz, G., \& Lubow, R. E. (1993). Amphetamineproduced attenuation of latent inhibition is modulated by stimulus preexposure duration: Implications for schizophrenia. Biological Psychiatry, 33, 707-711.

Dunn, L. A., Atwater, G. E., \& Kilts, C. D. (1993). Effects of antipsychotic drugs on latent inhibition-sensitivity and specificity of an animal behavioral model of clinical drug action. Psychopharmacology, 112, 315-323.

DunN, L. A., \& SCiBiLIA, R. J. (1996). Reaction time and pupil response measures show reduced latent inhibition in chronic schizophrenia. Society for Neuroscience Abstracts, 22, 239.

FELDON, J., \& WeINER, I. (1991). The latent inhibition model of schizophrenic attention disorder: Haloperidol and sulpiride enhance rats' ability to ignore irrelevant stimuli. Biological Psychiatry, 29, 635-646.

Gaffan, E. A., \& EacotT, M. J. (1995). A computer-controlled maze environment for testing visual memory in the rat. Journal of Neuroscience Methods, 60, 23-37.

Gluck, M. A., \& MYERS, C. E. (1993). Hippocampal mediation of stimulus representation: A computational theory. Hippocampus, 3, 491-516.

Gray, J. A., Feldon, J., Rawlins, J. N. P., Hemsley, D. R., \& Smith, A. D. (1991). The neuropsychology of schizophrenia. Behavioral \& Brain Sciences, 14, 1-84.

Gray, N. S., Pickering, A. D., Hemsley, D. R., Dawling, S., \& Gray, J. A. (1992). Abolition of latent inhibition by a single $5 \mathrm{mg}$ dose of d-amphetamine in man. Psychopharmacology, 107, 425-430.

Gray, N. S., Pilowsky, L. S., Gray, J. A., \& Kerwin, R. W. (1995). Latent inhibition in drug naive schizophrenics: Relationship to duration of illness and dopamine D2 binding using SPET. Schizophrenia Research, 17, 95-107.

HaLl, G. (1991). Perceptual and associative learning. New York: Oxford University Press.

Killcross, A. S., Dickinson, A., \& Robbins, T. W. (1994). Effects of the neuroleptic alpha-flupenthixol on latent inhibition in aversivelyand appetitively-motivated paradigms - evidence for dopaminereinforcer interactions. Psychopharmacology, 115, 196-205.

LiPP, O. V., \& VAITL, D. (1992). Latent inhibition in human Pavlovian differential conditioning: Effect of additional stimulation after preexposure and relation to schizotypal traits. Personality \& Individual Differences, 13, 1003-1012.

LuBow, R. E. (1989). Latent inhibition and conditioned attention theory. Cambridge: Cambridge University Press.

Lubow, R. E., \& GewiRTZ, J. C. (1995). Latent inhibition in humans: Data, theory, and implications for schizophrenia. Psychological Bulletin, 117, 87-103.

Lubow, R. E., InGBerg-Sachs, Y., Zalstein-Orda, N., \& Gewirtz, J. C. (1992). Latent inhibition in low and high "psychotic-prone" subjects. Personality \& Individual Differences, 13, 563-572.

Lubow, R. E., \& Josman, Z. E. (1993). Latent inhibition deficits in hyperactive children. Journal of Child Psychology \& Psychiatry, 34, 959-973.
Lubow, R. E., Weiner, I., \& SChnur, P. (1981). Conditioned attention theory. In G. H. Bower (Ed.), The psychology of learning and motivation (Vol. 15, pp. 1-49). New York: Academic Press.

Mackintosh, N. J. (1975). A theory of attention: Variations in the associability of stimuli with reinforcement. Psychological Review, 82, 276-298.

MOORE, J. W., \& Stickney, K. J. (1980). Formation of attentionalassociative networks in real time: Role of the hippocampus and implications for conditioning. Physiological Psychology, 8, 207-217.

Pearce, J. M., \& Hall, G. (1980). A model for Pavlovian learning: Variations in the effectiveness of conditioned but not unconditioned stimuli. Psychological Review, 87, 532-552.

Peters, S. L., \& JosePh, M. H. (1993). Haloperidol potentiation of latent inhibition in rats: Evidence for critical role at conditioning rather than preexposure. Behavioural Pharmacology, 4, 183-186.

Robisns, T. W. (1990). The case for frontostriatal dysfunction in schizophrenia. Schizophrenia Bulletin, 16, 391-402.

Ruob, C., ElSner, J., Weiner, I., \& Feldon, J. (1997). Amphetamineinduced disruption and haloperidol-induced potentiation of latent inhibition depend on the nature of the stimulus. Behavioural Brain Research, 88, 35-41.

Schmajuk, N. A., Lam, Y. W., \& Gray, J. A. (1996). Latent inhibition: A neural network approach. Journal of Experimental Psychology: Animal Behavior Processes, 22, 321-349.

Schmajuk, N. A., \& Moore, J. W. (1985). Real-time attentional models for classical conditioning and the hippocampus. Physiological Psychology, 13, 278-290.

Sotty, F., SANDNer, G., \& Gosselin, O. (in press). Latent inhibition in conditioned emotional response: c-fos immunolabelling evidence for brain areas involved in the rat. Brain Research.

Swerdlow, N. R., Braff, D. L., Hartston, H., Perry, W., \& Geyer, M. A. (1996). Latent inhibition in schizophrenia. Schizophrenia Research, 20, 91-103.

VAITL, D., \& LiPP, O. V. (1997). Latent inhibition and autonomic responses: A psychophysiological approach. Behavioural Brain Research, 88, 85-93.

WAGNER, A. R. (1976). Priming in STM: An information-processing mechanism for self-generated or retrieval-generated depression in performance. In T. J. Tighe \& R. N. Leaton (Eds.), Habituation: Perspectives from child development, animal behaviour, and neurophysiology (pp. 95-128). Hillsdale, NJ: Erlbaum.

WAGNER, A. R. (1978). Expectancies and the priming in STM. In S. H. Hulse, H. Fowler, \& W. K. Honig (Eds.), Cognitive processes in animal behavior (pp. 177-209). Hillsdale, NJ: Erlbaum.

WEINER, I. (1990). Neural substrates of latent inhibition: The switching model. Psychological Bulletin, 108, 442-461.

WeINER, I., \& FELDON, J. (1987). Facilitation of latent inhibition by haloperidol. Psychopharmacology, 91, 248-253.

WEINER, I., \& FELDON, J. (1997). The switching model of LI: An update of neural substrates. Behavioural Brain Research, 88, 11-25.

Weiner, I., Kidron, R., TARrasch, R., Arnt, J., \& Feldon, J. (1994). The effects of the new antipsychotic, sertindole, on latent inhibition in rats. Behavioural Pharmacology, 5, 119-124.

Weiner, I., Shadach, E., BARKaI, R., \& Feldon, J. (1997). Haloperidol and clozapine-induced enhancement of latent inhibition with extended conditioning: Implications for the mechanism of action of neuroleptic drugs. Neuropsychopharmacology, 16, 42-50.

Weiner, I., Shadach, E., Tarrasch, R., Kidron, R., \& Feldon, J. (1996). The latent inhibition model of schizophrenia: Further validation using the atypical neuroleptic, clozapine. Biological Psychiatry, 40, 834-843.

(Manuscript received April 22, 1997; revision accepted for publication September $17,1997$. 